\title{
Mathematical programming model for heat exchanger design through optimization of partial objectives
}

Viviani C. Onishi $^{a, b, c, *}$, Mauro A. S. S. Ravagnani ${ }^{a}$, José A. Caballero ${ }^{b}$

${ }^{a}$ Department of Chemical Engineering, State University of Maringá, Av. Colombo 5790, 87020-900, Maringá, PR, Brazil. E-mail addresses: pg51551@uem.br, ravag@deq.uem.br

${ }^{b}$ Department of Chemical Engineering, University of Alicante, Ap Correos 99, 03080 Alicante, Spain. E-mail address: caballer@ua.es

${ }^{c}$ CAPES Foundation, Ministry of Education of Brazil, Brasília - DF 70040-20, Brazil

* Corresponding author. Tel: +34 965903400. E-mail adress: pg51551@uem.br (Viviani C. Onishi).

\begin{abstract}
Mathematical programming can be used for the optimal design of shell-and-tube heat exchangers (STHEs). This paper proposes a mixed integer non-linear programming (MINLP) model for the design of STHEs, following rigorously the standards of the Tubular Exchanger Manufacturers Association (TEMA). Bell-Delaware Method is used for the shell-side calculations. This approach produces a large and non-convex model that cannot be solved to global optimality with the current state of the art solvers. Notwithstanding, it is proposed to perform a sequential optimization approach of partial objective targets through the division of the problem into sets of related equations that are easier to solve. For each one of these problems a heuristic objective function is selected based on the physical behavior of the problem. The global optimal solution of the original problem cannot be ensured even in the case in
\end{abstract}


which each of the sub-problems is solved to global optimality, but at least a very good solution is always guaranteed. Three cases extracted from the literature were studied. The results showed that in all cases the values obtained using the proposed MINLP model containing multiple objective functions improved the values presented in the literature.

Keywords: Mathematical programming; Mixed integer non-linear programming (MINLP); Heat exchanger design; Shell-and-tube heat exchanger (STHE); Sequential optimization

\section{Introduction}

Optimal heat recuperation is fundamental in solving the problem of efficient energy usage and consequently to promote the reduction of gas emissions and fuel consumption. Since nearly $80 \%$ of the total energy consumption is related to heat transfer, improvement on heat transfer performance is of great significance to the reduction of the energy consumption [1-4]. In this perspective, heat exchangers are one of the most efficient types of heat transfer equipment used to recover heat between two process fluids [5,6]. Shell-and-tube heat exchangers (STHEs) are widely used in industrial chemical processes, plants, power and process industries because of their great adaptability to different operational conditions, strength characteristic and design flexibility. However, the design of STHEs, including thermodynamic and fluid dynamic design, cost estimation and optimization, is a complex process involving the integration of design rules and empirical knowledge from several areas, especially for the shell-side that presents complex characteristics of heat transfers and pressure drop [7]. 
The design of STHEs involves the determination of a large number of thermalhydraulic and operative variables for obtaining the optimum geometry, satisfying the required amount of heat and the set of constraints imposed by the process [6,7]. In the last decade, due to the important role developed by the STHEs within the industrial context, a considerable research effort has been devoted to solving the optimization problem of this type of equipment. Thus, several researchers used different optimization techniques: i.e. genetic algorithms [8-11], particle swarm optimization [6], and mathematical programming [7,12-14], to improve the design of this type of heat exchangers by optimizing different objectives like the annual cost, including area expenses and/or pumping costs $[6,7,9,12-14]$ or entropy generation $[11,15,16]$. Other studies have been dedicated to the optimization of a single geometric parameter, such as the spacing of baffles $[17,18]$, or a variety of geometric and operational parameters of STHEs [19].

Different design methods have also been proposed. The first method for determining the thermal-hydraulic parameters, heat exchange area, heat transfer coefficients and pressure drop was published by Kern [20]. The method of Kern was developed for designing heat exchangers or to evaluate existing equipment with regard to pressure drop and fouling. In this method, correlations were obtained based on equivalent diameter, overestimating the design parameters for the shell-side [7]. According to Taborek [21], the method of Bell-Delaware provides more realistic and accurate results for the shell-side concerning the heat transfer coefficients and pressure drop, due to the consideration of five different streams (i.e. leakages between tubes and baffles, bypass of the tube bundle without cross flow, leakages between shell and baffles, leakages due to more than one tube pass and the main stream and tube bundle cross flow), that were not taken into account in the method of Kern [20]. 
These streams do not occur in well-defined regions, but interact between them, needing a complex mathematical treatment to represent the real shell-side flow.

In a previous study, Mizutani et al. [12] presented an optimization procedure for the design of STHEs using the Bell-Delaware Method for calculating the heat transfer coefficients and pressure drop to the shell-side. The authors used generalized disjunctive programming (GDP) for problem formulation and a MINLP reformulation for its solution. The model did not follow the TEMA standards [22], thus some characteristics as number of tubes and tube bundle diameter, which are calculated and optimized, may not conform to the standards. In Ravagnani and Caballero [7], the Bell-Delaware Method is used to formulate a mathematical model involving continuous and discrete variables for selection of an optimal configuration of a shelland-tube heat exchanger. Just as in Mizutani et al. [12], the model is based on GDP and is optimized with a MINLP formulation, but in this case rigorously following all the TEMA standards, it was possible to find all the mechanical characteristics such as shell diameter, tube bundle diameter, tube external diameter, pitch, arrangement of tubes, number of tube passes and number of tubes.

The use of a detailed process model results in a highly non-convex MINLP problem. It is important to remark that even the best state of the art deterministic solvers cannot guarantee the global optimal solution. As the probability of the solution to become trapped in a local optimum is large, it is of interest to study other optimization strategies avoiding such a situation. This paper presents a computeraided approach for STHEs thermal and hydraulic design, based on the Bell-Delaware Method to formulate a MINLP model for the selection of the optimum equipment configuration. The proposed model follows rigorously the TEMA standards [22], has been optimized using mathematical programming and solved with the software 
GAMS. A new approach of sequential optimization was developed through the use of diverse objective targets. With this purpose, the problem was divided into sets of equations. In each one of these sets the knowledge of the physical behavior of the system allows introducing an objective that likely will produce the optimal performance in the final design. Three case studies for different STHEs applications are presented. Even though the optimal solution is not guaranteed (i.e. total annual cost), good results are expected.

\section{Problem Statement}

The design of heat exchangers consists of determining the optimal STHE for heat transfer between a hot stream and a cold stream. This design problem can be formulated as an optimization problem whose main objective is to determine the equipment characteristics that present a minimal area and/or cost, considering the expenses concerning the heat exchange area and pumping costs associated with the pressure drop.

These characteristics should strictly follow the TEMA standards [22] and the final design of the equipment must comply with the pressure drop, fouling limits and fluid speed imposed by the process. Inlet data for both hot and cold fluids are: $T_{\text {in }}$ (inlet temperature), $T_{\text {out }}$ (outlet temperature), $m$ (mass flow), $\rho$ (density), $C p$ (heat capacity), $\mu$ (viscosity), $k$ (thermal conductivity), allowable $\Delta P_{\text {design }}$ (pressure drop), $r d_{\text {design }}$ (fouling factor) and area cost data. The index $\mathrm{h}$ is used for the hot fluid and the index $_{\mathrm{c}}$ for the cold fluid. The mechanical variables to be optimized are internal diameter (din), external diameter (dex), geometric arrangement (arr), tube pitch ( $p t)$, length $(L)$, number of passes (Ntp) and number of tubes $(N t)$ for the tube-side. To the shell-side, the variables to be determined are the shell external diameter (Ds), the tube 
bundle diameter (Dotl), the baffles number $(\mathrm{Nb})$, the baffles cut $(l c)$ and the spacing between them (ls). Finally, the thermal-hydraulic variables to be found are heat duty $(Q)$, the heat exchange area $(A)$, the tube-side and shell-side film coefficients $\left(h^{t}\right.$ and $h^{s}$ ), the dirty and clean overall heat transfer coefficient ( $U d$ and $\left.U c\right)$, the shell-side and tube-side pressure drop $\left(\Delta P^{t}\right.$ and $\left.\Delta P^{s}\right)$, the fouling factor $(r d)$, and the fluids location inside the heat exchanger.

\section{Mathematical modeling of STHEs}

A comprehensive description of the model is presented in the following paragraphs. In this approach, instead of solving the complete set of equations, a sequential approach was followed taking advantage of the designer's knowledge on how a STHE should work. The design equations were divided into sets. The optimal value of the variables in each set is fixed in the following optimizations.

In this model, the Bell-Delaware Method was used for the calculation of the heat transfer coefficients and the pressure drop in the shell-side. Moreover, the model is formulated as a generalized disjunctive programming (GDP) problem and reformulated as a MINLP problem [7,12]. Moreover, the physical properties (density, viscosity, heat capacity and thermal conductivity) are assumed to be constant (temperature invariant).

1. The first set of equations consists in a MINLP problem with the determination of the best location inside the heat exchanger for the hot and cold fluids, as well as with the estimation of some geometric parameters according to the TEMA standards [22] (See next paragraphs for a complete list of all the geometric parameters optimized in this first problem) and the definition of the flow regime and fluid velocity in the shell- 
side. The fluids allocation in STHEs must consider some important issues like the materials of construction, fouling, operating pressures, pressure drops, fluids viscosity, flowrates, and temperatures. Therefore, usually the decision of fluids allocation in the tube-side or in the shell-side is taken a priori. However, if the designer has all this information and is not sure in which side must be allocated the fluids, a mathematical approach can be used to define it. Obviously, this decision belongs to the designer. Thus, in this set the choice of the fluid flow side is done on the basis of binary variables $y_{1}{ }^{f}$ and $y_{2}{ }^{f}$. If $y_{1}{ }^{f}=1$ the hot fluid flows in the tube-side. This implies that the physical properties and mass flow of the hot fluid will be allocated on the tube-side, if $y_{1}{ }^{f}=0$ the reverse occurs. The GDP formulation is shown in the Eq. (GDP-1)-(3) and the MILP reformulation in Eqs. (1)-(37).

$$
\left[\begin{array}{c}
y_{1}{ }^{f} \\
m^{t}=m^{h} \\
m^{s}=m^{c} \\
C p^{t}=C p^{h} \\
C p^{s}=C p^{c} \\
\mu^{t}=\mu^{h} \\
\mu^{s}=\mu^{c} \\
k^{t}=k^{h} \\
k^{t}=k^{c} \\
\rho^{t}=\rho^{h} \\
\rho^{s}=\rho^{c}
\end{array}\right] \vee\left[\begin{array}{c}
y_{2}{ }^{c} \\
m^{t}=m^{h} \\
m^{s}=m^{c} \\
C p^{t}=C p^{h} \\
C p^{s}=C p^{c} \\
\mu^{t}=\mu^{h} \\
\mu^{s}=\mu^{c} \\
k^{t}=k^{h} \\
k^{t}=k^{c} \\
\rho^{t}=\rho^{h} \\
\rho^{s}=\rho^{c}
\end{array}\right]
$$

(GPD-1)

$y_{1}^{f}+y_{2}^{f}=1$

$m^{h}=m_{1}{ }^{h}+m_{2}{ }^{h}$

$m^{c}=m_{1}^{c}+m_{2}^{c}$

$m^{t}=m_{1}^{h}+m_{1}^{c}$

$m^{s}=m_{2}{ }^{h}+m_{2}{ }^{c}$ 


$$
\begin{aligned}
& m_{1}{ }^{h} \leq m^{\text {upper }} y_{1}{ }^{f} \\
& m_{1}{ }^{c} \leq m^{\text {upper }} y_{2}{ }^{f} \\
& m_{2}{ }^{h} \leq m^{u p p e r} y_{2}{ }^{f} \\
& m_{2}{ }^{c} \leq m^{\text {upper }} y_{1}{ }^{f} \\
& \mu^{t}=y_{1}{ }^{f} \mu^{h}+y_{2}{ }^{f} \mu^{c} \\
& \mu^{s}=y_{2}{ }^{f} \mu^{h}+y_{1}{ }^{f} \mu^{c} \\
& C p^{t}=y_{1}{ }^{f} C p^{h}+y_{2}{ }^{f} C p^{c} \\
& C p^{s}=y_{2}{ }^{f} C p^{h}+y_{1}{ }^{f} C p^{c} \\
& k^{t}=y_{1}{ }^{f} k^{h}+y_{2}{ }^{f} k^{c} \\
& k^{s}=y_{2}{ }^{f} k^{h}+y_{1}{ }^{f} k^{c} \\
& \rho^{t}=y_{1}{ }^{f} \rho^{h}+y_{2}{ }^{f} \rho^{c} \\
& \rho^{s}=y_{2}{ }^{f} \rho^{h}+y_{1}{ }^{f} \rho^{c}
\end{aligned}
$$

To define the shell diameter (Ds), tube bundle diameter (Dotl), tube external diameter (dex), geometric arrangement (arr), tube pitch (pt), number of tube passes (Ntp) and tube number (Nt), a table containing the respective values was constructed in accordance with TEMA standards, as shown in Table 1. For the construction of this table 2 types of tube external diameters were considered, 25.4 and 19.05 mm, two types of geometrical arrangement, triangular and square, three types of tube pitch, 23.79, 25.4, and $31.75 \mathrm{~mm}$, five types of tube passes, 1, 2, 4, 6, 8, and 21 different types of shell diameter and tube bundle diameter, ranging from $0.205 \mathrm{~m}$ and $0.173 \mathrm{~m}$ to $1.524 \mathrm{~m}$ and $1.473 \mathrm{~m}$, respectively, with 565 lines. Obviously, other values can be 
added to this table. The GDP formulation proposed by Mizutani et al. [12] was used to find these geometric parameters according to the Eqs. (19)-(26).

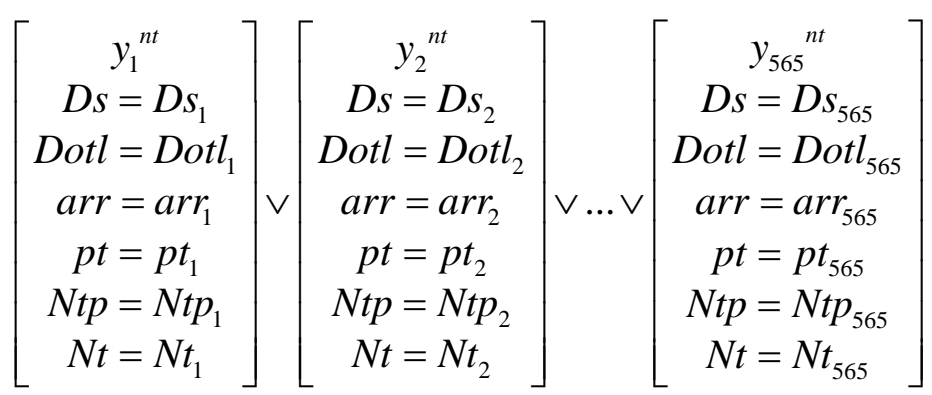

(GPD-2)

$D s=\sum_{i=1}^{565} D s_{i} y_{i}^{n t}$

$\operatorname{Dotl}=\sum_{i=1}^{565} \operatorname{Dotl}_{i} y_{i}^{n t}$

$\operatorname{dex}=\sum_{i=1}^{565} \operatorname{dex}_{i} y_{i}^{n t}$

$\operatorname{arr}=\sum_{i=1}^{565} \operatorname{arr}_{i} y_{i}^{n t}$

$p t=\sum_{i=1}^{565} p t_{i} y_{i}^{n t}$

$N t p=\sum_{i=1}^{565} N t p_{i} y_{i}^{n t}$

$N t=\sum_{i=1}^{565} N t_{i} y_{i}^{n t}$

$\sum_{i=1}^{565} y_{i}^{n t}=1$

Five types of tube length were used according to TEMA standards as shown in the Eq. (27) and Eq. (28). 


$$
\begin{aligned}
& N_{L}=\{2.438,3.658,4.877,6.096,6.706\} \\
& L=2.438 y_{1}{ }^{L}+3.658 y_{2}{ }^{L}+4.877 y_{3}{ }^{L}+6.096 y_{4}{ }^{L}+6.706 y_{5}{ }^{L} \\
& \sum_{i=1}^{5} y_{i}{ }^{L}=1
\end{aligned}
$$

According to TEMA standards, the baffle space (ls) should be located between the values of Ds and Ds/5. In this case, the values obtained through the Eq. (29) and Eq. (30) were considered.

$$
\begin{aligned}
& l s \leq D s \\
& l s \geq D s / 5
\end{aligned}
$$

The shell-side fluid velocity was obtained by the Eq. (31). According to Smith [23] this value must be constrained to $0.5 \leq v^{s}(\mathrm{~m} / \mathrm{s}) \leq 2$.

$$
v^{s}=\left(m^{s} / \rho^{s}\right) /(D s / p t)(p t-d e x) l s
$$

In this first set, the maximization of the shell-side Reynolds number was considered an objective function as shown in Eq. (32). The selection of this objective function is related to the fact that in heat transfer, any elevation in the fluid flow velocity will imply the increase of the coefficient of heat transfer by convection and hence the overall heat transfer coefficient. This will entail a smaller heat exchange area and therefore cheaper equipment. It was assumed that the shell-side is the more critical in this first step, and therefore the tube-side optimization can be left for the next steps. 
Where $S m$ is the cross-flow at/or near centerline for one cross-flow section.

Sm can be found by the following disjunction:

$$
\left[\begin{array}{c}
y_{t r i}^{a r r} \\
S m=l s(D s-D o t l+(p t-d e x)(\operatorname{Dotl}-d e x) / p t)
\end{array}\right] \vee\left[\begin{array}{c}
y_{s q}^{a r r} \\
S m=l s(D s-D o t l+(p t-\operatorname{dex})(\operatorname{Dotl}-\operatorname{dex}) / p n)
\end{array}\right]
$$

Using a big-M reformulation:

$$
\begin{aligned}
& S m \leq l s(\text { Ds }- \text { Dotl }+(p t-d e x)(\text { Dotl }- \text { dex }) / p t)+M\left(1-y_{t r i}{ }^{a r r}\right) \\
& S m \geq l s(\text { Ds }- \text { Dotl }+(p t-d e x)(\text { Dotl }- \text { dex }) / p t)-M\left(1-y_{t r i}{ }^{a r r}\right) \\
& S m \leq l s(D s-\text { Dotl }+(p t-d e x)(\text { Dotl }- \text { dex }) / p n)+M\left(1-y_{t r i}{ }^{a r r}\right) \\
& S m \geq l s(D s-\text { Dotl }+(p t-d e x)(\text { Dotl }- \text { dex }) / p n)-M\left(1-y_{t r i}{ }^{a r r}\right) \\
& y_{t r i}{ }^{a r r}+y_{s q}{ }^{a r r}=1
\end{aligned}
$$

Where $\mathrm{M}$ is a parameter large enough to be a valid upper bound in equations (33) - (37). It is important to point out that if $\mathrm{M}$ is smaller than the upper bound for the function, this situation may cut off valid solutions. If $\mathrm{M}$ is too large, the model may become numerically difficult to solve. Hence, the value of the $\mathrm{M}$ term needs to be chosen carefully.

In the (GPD-1) and (GPD-2), the convex hull reformulation was used, while in the GPD-3 the big-M formulation was preferred. In the choice between the convex hull and the big-M reformulation, some points should be considered. According to 
Vecchietti et al. [24], the big-M relaxation is more convenient to use when the problem size does not increase substantially when compared to the convex hull relaxation. Moreover, the big-M model is competitive when good bounds can be provided for the variables, and for large problems where it is important to keep the number of equations and variables as small as possible [25]. It should be mentioned that for proper disjunctions where the feasible regions have some intersection, the objective function plays an important role, if the minimizer of the objective function is inside the feasible region of the disjunctive set, both the big-M and the convex hull relaxation may yield the same relaxation value. Otherwise the convex hull should be generally better, but the big-M constraints with appropriate bounds can be competitive. However, generally the lower bound by big-M relaxation is weaker, which may require longer CPU time than the convex hull relaxation [24]. In this specific case, the convex hull reformulation was used for all disjunctions that involve linear equations, while the big-M reformulation was used for the disjunction that involve non-linear equations to decrease the number of non-convexities.

2. In this set of equations the objective was the minimization of the shell-side pressure drop. The maximization of the Reynolds number in stage 1 , favors the heat transfer, but also implies a larger velocity. In this stage, the rest of geometrical parameters for the shell-side were selected in such a way that a high velocity produces a smaller pressure drop in the shell. In the next paragraph a complete list of all the parameters optimized in this second problem is presented. Of course, all physical and geometrical parameters optimized in the first step are maintained constant in this sub-problem. 
The second set of equations is a MINLP problem as shown in the Eqs. (38)(54), and comprises the calculation of the Fanning's factor $\left(f l^{s}\right)$; the Colburn's factor (ji) and geometrical parameters such as the baffles number $(\mathrm{Nb})$; number of rows of tubes in ideal cross-flow $(N c)$; fraction of total tubes in cross-flow $(F c)$, number of tube columns effectively crossed in each window $(\mathrm{Ncw})$; calculation of correction factor for baffle configuration effects $(J c)$; correction factor for baffle-leakage effects $(\mathrm{Jl})$ and correction factor for bundle-bypassing effects $(\mathrm{Jb})$; shell-side film coefficient $\left(h^{S}\right)$ and shell-side pressure drop $\left(\Delta P^{S}\right)$.

$$
\begin{aligned}
& f l^{s}=b_{1} 1.064^{b}\left(\mathrm{Re}^{s}\right)^{b_{2}} \\
& j i=a_{1} 1.064^{a}\left(\mathrm{Re}^{s}\right)^{a_{2}}
\end{aligned}
$$

Where $a$ and $b$ are empirical correlations and $a_{1}, a_{2}, b_{1}$ and $b_{2}$ are coefficients that relate the shell-side Reynolds number with the tube arrangement as presented in [7].

$$
\begin{aligned}
& N b=L / l c-1 \\
& N c=D s[1-2(l c / D s)] / p p
\end{aligned}
$$

Where $l c$ is the baffle cut given to $l c=0.25 D s$.

$$
F C=1 / \pi[\pi+2 \lambda \sin (\arccos (\lambda))-2 \arccos (\lambda)]
$$

With $\lambda=(D s-2 l c) /$ Dotl 
$N c w=0.8 l c / p p$

$J_{C}=F_{C}+0.54(1-F C)^{0.345}$

$J l=\alpha+(1-\alpha) \exp (-2.2(S s b+S t b) / S m)$

With $\alpha=0.44(1-S s b /(S s b+S t b))$

$J b=\exp (-0.3833 F s b p)$

$h^{s}=h_{0} i \cdot J C \cdot J l \cdot J b$

With $h_{0} i=j i \cdot C p^{s} \cdot m^{s} / S m\left(k^{s} / C p^{s} \mu^{s}\right)^{2 / 3}$

$\Delta P^{s}=2 \Delta P_{b i}(1+N c w / N c) R b+(N b+1) \Delta P_{b i} \cdot R b+N b \cdot \Delta P_{w i} \cdot R l$

With $\Delta P_{b i}=2 f l^{s} \cdot N c\left(m^{s}\right)^{2} / \rho^{s}(S m)^{2}$

And $\Delta P_{w i}=(2+0.6 N c w)\left(m^{s}\right)^{2} / 2 S w \cdot \rho^{s} \cdot S m$

This value should respect the pressure drop limit fixed a priori in the design:

$\Delta P^{s} \leq \Delta P_{\text {design }}$

3. The third set of equations is a NLP problem to optimize the fluid velocity $\left(v^{t}\right)$ and Reynolds number $\left(R e^{t}\right)$ in the tube-side. In this case, again the maximization of the Reynolds number in the tube side is considered. All physical and geometrical parameters optimized in the previous steps are maintained constant in this set. This 
sub-problem comprises the Eqs. (55)-(57) as well as the constraint for the fluids velocity in the tube-side.

$v^{t}=\operatorname{Re}^{t} \cdot \mu^{t} / \rho^{t} \cdot \operatorname{din}$

With $1 \leq v^{t}(m / s) \leq 3$

$\operatorname{Re}^{t}=4 m^{t} \cdot N t p / \pi \cdot \operatorname{din} \cdot \mu^{t} \cdot N t$

4. In the following set of design equations, the values for the Fanning's factor $\left(\mathrm{fl}^{\mathrm{t}}\right)$, Prandtl's number $\left(\mathrm{Pr}^{t}\right)$, Nusselt's number $\left(N u^{t}\right)$, heat transfer coefficient $\left(h^{t}\right)$, and pressure drop $\left(\Delta P^{t}\right)$, are obtained and optimized to the tube-side. Here, the pressure drop minimization was regarded as an objective function. Note that all physical and geometrical parameters optimized in the previous steps are maintained constant in this sub-problem. This set of equations is a NLP problem and is shown in Eqs. (58)-(63), as well as the constraint for the tube-side pressure drop.

$1 / \sqrt{f l^{t}}=-4 \log \left[0.27 \varepsilon / \operatorname{dex}+\left(7 / \mathrm{Re}^{t}\right)^{0.9}\right]$

Where $\varepsilon$ is the roughness in $\mathrm{mm}$.

$$
\begin{aligned}
& \operatorname{Pr}^{t}=\mu^{t} C p^{t} / \kappa^{t} \\
& N u^{t}=0.027\left(\operatorname{Re}^{t}\right)^{0.8}\left(\operatorname{Pr}^{t}\right)^{1 / 3} \\
& h^{t}=\left(N u^{t} \cdot \kappa^{t} / \operatorname{din}\right)(\operatorname{din} / \operatorname{dex}) \\
& \Delta P^{t}=\left(1 / \rho^{t}\right)\left(2 f l^{t} \cdot N t p \cdot L\left(v^{t}\right)^{2} / \operatorname{din}+1.25 N t p\left(v^{t}\right)^{2}\right)
\end{aligned}
$$


With the restriction $\Delta P^{t} \leq \Delta P_{\text {design }}$

5. The last set is a NLP problem with the purpose of the determination of the heat duty $(Q)$, the log mean temperature difference (LMTD), the correction factor for the LMTD (Ft) calculated according to [26], fouling factor $(r d)$, the heat exchange area $(A)$, clean overall heat transfer coefficient $(U c)$, dirty overall heat transfer coefficient $(U d)$ and the total cost $\left(C_{\text {total }}\right)$. The heat exchange area minimization was considered as an objective function, and if the cost parameters are available, the total cost minimization considering expenses associated with area and/or pumping costs, also was considered as an objective function. Again, all physical and geometrical parameters optimized in the previous steps are maintained constant for the optimization of this sub-problem. This set of equations is shown in Eq. (64)-(72).

$$
\begin{aligned}
& Q=m^{s} \cdot C p^{s}\left(T_{\text {in }}{ }^{h}-T_{\text {out }}{ }^{h}\right)^{s} \quad \text { or } \quad Q=m^{s} \cdot C p^{s}\left(T_{\text {in }}{ }^{c}-T_{\text {out }}{ }^{c}\right)^{s} \\
& Q=m^{t} \cdot C p^{t}\left(T_{\text {in }}{ }^{h}-T_{\text {out }}{ }^{h}\right)^{t} \quad \text { or } \quad Q=m^{t} \cdot C p^{t}\left(T_{\text {in }}{ }^{c}-T_{\text {out }}{ }^{c}\right)^{t} \\
& \operatorname{LMTD}=\left(\theta_{1}-\theta_{2}\right) / \ln \left(\theta_{1} / \theta_{2}\right)
\end{aligned}
$$

Where $\theta_{1}=T_{\text {in }}{ }^{h}-T_{\text {out }}{ }^{c}$ and $\quad \theta_{2}=T_{\text {out }}{ }^{h}-T_{\text {in }}{ }^{c}$

$$
\begin{aligned}
& A=N t \cdot \pi \cdot \operatorname{dex} \cdot L \\
& U d=Q / A \cdot L M T D \cdot F t \\
& U C=1 /\left(\operatorname{dex} / \operatorname{din} \cdot h^{t}+r_{\text {in }} \cdot \operatorname{dex} / \operatorname{din}+\operatorname{dex} \cdot \ln (\operatorname{dex} / \operatorname{din}) / 2 k^{t}+r_{e x}+1 / h^{s}\right) \\
& r d=(U c-U d) U C \cdot U d
\end{aligned}
$$

Where $r d \geq r d_{\text {design }}$ 


$$
C_{\text {total }}=C_{\text {area }}+C_{\text {pump }}=a_{c}(Q / U \cdot F t \cdot L M T D)^{b_{c}}+C_{c}\left(\Delta P^{t} \cdot m^{t} / \rho t+\Delta P^{s} \cdot m^{s} / \rho^{s}\right)
$$

For fluids with high viscosity, the wall viscosity corrections for heat transfer coefficients, friction factors and pressure drop calculations, could be included in the model if the dependence relation between viscosity and temperature is available. If available, the tubes temperature could be calculated and the viscosity estimated with respect to these temperatures. For non-viscous fluids, however, these correction factors can be neglected.

It is relevant to remark that the presented optimization sequence should be followed in this exact order and the optimal value of the variables in each set is fixed in the following optimizations. Furthermore, this methodology allows finding the minimum area for heat exchange if the cost parameters are not evaluated. The conceptual representation of the model showing the structure of the sequential model is presented in Fig. 1. Note that the objective function in each sub-problem is selected in order to get a feasible design that tends to be also an optimal design for the economic point of view by favoring the heat transfer or limiting the pressure drop. It is crucial to understand, however, that this sequential approach cannot guarantee the global optimum even in the case in which each sub problem is solved to global optimality, but it is expected a very good design, as proved by the following examples.

\section{Case studies}

Three examples from the literature were studied, contemplating different situations, to analyze the performance of the developed model as to obtain the optimal design of STHEs. 
Case 1. The first example is taken from Shenoy [28]. In this case, no data is available for area expenses and by pumping fluid, thus the final objective of this problem consists in achieving a minimal heat exchange area. The temperatures of input and output of hot and cold fluids, as well as their physical properties and fouling factor are shown in Table 2. For this case, the thermal conductivity of the tube equal to 50 $\mathrm{Wm} / \mathrm{K}$ and the roughness factor $4.57 \mathrm{e}-5$ were considered. The dirt resistance factor was maintained in $1.5 \mathrm{e}-4 \mathrm{~m}^{2} \mathrm{~K} / \mathrm{W}$ for each side. The project was regarded as single shell, because this is sufficient to satisfy the thermal balance for the fluids considered, since at these temperatures the correction factor for LMTD is greater than 0.75 . The design features were evaluated for two different pressure ranges for both sides, in order to analyze the effect of pressure on the geometrical and thermal-hydraulic design. Thus, it was considered a limit pressure drop of $10 \mathrm{kPa}$ for the shell-side and $45 \mathrm{kPa}$ for the tube-side, and subsequently pressure drops $60 \mathrm{kPa}$ for both shell and tube-sides were applied.

The results obtained using the proposed model in this work are shown in Table 3, where are also displayed the configurations of heat exchangers obtained by Shenoy [28] and Ravagnani and Caballero [7]. In their work, the authors Ravagnani and Caballero [7] solved the problem proposed by Shenoy [28] considering the standardization contained in TEMA [22], which was not considered by Shenoy [28]. The heat exchange area obtained by Shenoy [28] was $28.40 \mathrm{~m}^{2}$, whereas with the model proposed by Ravagnani and Caballero [7], values of $28.31 \mathrm{~m}^{2}$ without fixing the location of hot fluid and $38.52 \mathrm{~m}^{2}$ fixing it in the shell-side were attained, as their model allowed to choose the best location of the fluid in the exchanger, which was also disregarded in study of Shenoy [28]. However, using the systematic optimization of sets of equations, with the adoption of multiple objective functions, proposed in 
this paper, it was possible to obtain values for the heat exchange area of $28.31 \mathrm{~m}^{2}$ without the fastening of fluids in the STHEs and $28.89 \mathrm{~m}^{2}$ considering the hot fluid fixed inside the shell-side, for the first case where the pressures were maintained at 10 $\mathrm{kPa}$ and $45 \mathrm{kPa}$ for shell and tube-sides, respectively. For the second case, in which the pressure shell-side and tube-side were both maintained at $60 \mathrm{kPa}$, results for the heat exchange area of $26.41 \mathrm{~m}^{2}$ without the assumptions on the fluids location and $27.73 \mathrm{~m}^{2}$ maintaining the hot fluid in the shell-side were obtained.

In order to verify the accuracy of the proposed method, a rating approach simulation in software ASPEN PLUS was done. For the first case $(\triangle P=10 \mathrm{kPa}$ and $\Delta P=45 \mathrm{kPa}$ for shell and tube-sides, respectively), values of $27,91 \mathrm{~m}^{2}$ (without the fastening of fluids in the STHEs), and $28.49 \mathrm{~m}^{2}$ (considering the hot fluid fixed inside the shell-side) were obtained for the heat exchanger area. In the second case, wherein the pressure in the shell-side and tube-side were both maintained at $60 \mathrm{kPa}$, results for the heat exchange area of $26.04 \mathrm{~m}^{2}$ (without the assumptions on the fluids location), and $27.34 \mathrm{~m}^{2}$ maintaining the hot fluid in the shell-side were obtained. In all cases, the values presented in Table 3 were considered, i.e., $Q=4339.4 \mathrm{~kW}, L M T D=60.78$, $\Delta P$ of the hot-side, and the respective dirty overall heat transfer coefficient. The results obtained with the proposed method presented in this paper and the results obtained with the simulation approach in ASPEN PLUS are very similar, proving the accuracy of the model proposed. The small differences found between them may be assigned to the equipment standardization considered in the proposed model.

Usually the logarithmic mean temperature difference (LMTD) operator is reformulated using the Chen [29] approximation to avoid the numerical problem that appears if the temperature difference at both extremities of the heat exchanger is the same. However, the probability of this error is small and therefore, in this work, the 
LMTD was not obtained by the approach of Chen [29], as used in the study of Ravagnani and Caballero [7], and thus a more realistic LMTD of 60.78 was achieved. Moreover, the correction factor was calculated for LMTD as 0.985, and not held fixed as an input parameter. The implementation of these equations in the proposed model resulted in best values for the heat exchanger configuration obtained, as in comparison with the published literature.

Case 2. The second case studied was extracted from Mizutani et al. [12]. Table 2 shows the cost data, temperatures, flowrates and physical properties of the fluids for this example. In addition, the thermal conductivity of the tubes wall, $50 \mathrm{~W} / \mathrm{mK}$, and the leakage between baffles and tubes, and between baffles and shell, 2.5 and $8 \mathrm{~mm}$, respectively, are also provided. The pressure limits must be fixed at $68.95 \mathrm{kPa}$, as suggested by Kern [20], since the fluids are in liquid-phase. A dirt resistance factor of 1.5e- $4 \mathrm{~m}^{2} \mathrm{KW}^{-1}$ should be provided on each side.

As previously commented, the final objective in the model must be the obtention of a minimal heat exchange area or a minimal total cost. According to Hall et al. [27], some rigorous parameters (usually constants) can be aggregated in the cost equation, considering mixed materials of construction, pressure ratings and different exchangers types. In this case, the authors proposed an objective function composed by the sum of area and pumping cost. The pumping cost is given by the equation:

$$
C_{\text {pump }}=C_{c}\left(\Delta P^{t} \cdot m^{t} / \rho^{t}+\Delta P^{s} \cdot m^{s} / \rho^{s}\right)
$$

The final function to be minimized is the total annual cost, given by the equation: 


$$
C_{\text {total }}=a_{c}(A)^{b_{c}}+C_{\text {pump }}
$$

Where $a_{c}=123, b_{c}=0.59$ and $c_{c}=1.31$.

Table 4 presents a comparison between the problem solved by Mizutani et al. [12], Ravagnani and Caballero [7] and the model proposed in this paper. Two situations were studied, considering or disregarding the hot fluid fixed in the shellside. In both cases, the annual cost obtained is lower than the values calculated by these authors. Moreover, keeping the same amount of heat exchanged, there was a significant reduction of the heat exchange area in both cases.

In the first set of equations, the geometric parameters of the heat exchanger are determined. In this example, a result slightly higher than the value obtained in [7] was found to the tube internal diameter (when the hot fluid is fixed to the shell-side), while for the tube external diameter the same value $(25.04 \mathrm{~mm})$ was calculated. In addition, the values obtained for the shell diameter (Ds), tube bundle diameter (Dotl) and number of tubes (Nt), are lower than those registered by Ravagnani and Caballero [7], thus requiring a greater tube length to satisfy the energy balance. However, it should be noted that larger tubes favor the heat exchange although they increase the pressure drop. Moreover, as demonstrated by Kern [20], it is more economical to build longer heat exchangers with smaller shell diameter. On the other hand, higher pressure drops generate higher pumping expenses, requiring a cost-effective balance to support the equipment design. This balance was reached in the following sets, with the minimization of the pressure drop in both shell and tube sides.

Using the MINLP proposed in the present paper, even if the hot fluid is fixed in the shell-side, the value of the objective function for the last set is smaller than in the work of Ravagnani and Caballero [7]. Analyzing the sensibility of the final cost 
two significant aspects must be considered, the area cost and the pumping cost. In the case studied the proposed MINLP model presents areas equal or lower (264.6 and $247.2 \mathrm{~m}^{2}$ versus 264.6 and $286.6 \mathrm{~m}^{2}$ ) than those obtained in [7], due to the values of the geometric parameters obtained anteriorly. As the area cost is smaller, the global cost is lower than the values obtained by Mizutani et al. [12] and by Ravagnani and Caballero [7] (4820.21 \$/year and 5134.21 \$/year versus 5028.29 \$/year and 5191.47 \$/year, respectively).

Case 3. The third example is taken from Serna and Jiménez [30]. Table 2 shows the data from the input and output temperatures and flowrates of streams, as well as their physical properties and fouling factors. It is assumed that the thermal conductivity of the tube is $45 \mathrm{Wm} / \mathrm{K}$. In this case, the pressure in the shell-side was maintained at $83.69 \mathrm{kPa}$ and $76.74 \mathrm{kPa}$ for the tube-side. Again, a single shell is enough to satisfy the heat balance, since the correction factor for the LMTD is 0.917, greater than 0.75, as suggested in the literature.

Serna and Jiménez [30] present an efficient and robust algorithm for the design of STHEs based on the Bell-Delaware method. The algorithm makes full use of the maximum rated pressure for both shell and tube-sides, in order to obtain a heat exchanger under extreme pressure drop. In this case, as the cost data is not available, the authors considered as objective function the minimization of the heat exchange area.

Table 5 shows three STHEs configurations for this example. The first column presents the results obtained by Serna and Jiménez [30] through their Bell-Delaware Method based algorithm. The second column shows the configuration obtained by Ravagnani and Caballero [7] using a MINLP model also based on the method of Bell- 
Delaware, but using the TEMA standards [22]. The last column shows the heat exchanger configuration obtained using the MINLP algorithm proposed in this paper. The heat exchange areas obtained are $163.97 \mathrm{~m}^{2}, 148.56 \mathrm{~m}^{2}$ and $139.12 \mathrm{~m}^{2}$, respectively. Serna and Jiménez [30] did not make use of existing standards in TEMA [22], so the final configuration of STHE obtained contains values for geometric characteristics such as tube length and shell-and-tube diameters out of standard specifications.

In this work, the MINLP model proposed follows strictly the standards TEMA [22], the improvements presented with this sequential approach, proves that likely, previous models were trapped in local optimal solutions proving the efficiency of the proposed approach. Additionally, three more cases have been studied for comparison with other optimization methods, and the obtained results were also good (see supplementary material). All the examples have been solved with the software GAMS, using the SBB solver for the MINLP sets and the CONOPT3 solver for the NLP problems. In all cases the same processor Intel ${ }^{\circledR}$ Pentium ${ }^{\circledR}$ Duo $2.00 \mathrm{GHz}$ was used, with processing times below the 20s. For the type of problem studied in the present paper, note that these solvers can ensure only a local optimum. However, the reduced size of the sub problems tends to avoid these local optima solutions or at least minimize their incidence on the final solution. In any non-convex optimization problem, the gradient based algorithms (deterministic optimization) can only assure local optima. Although the advances in deterministic algorithms for global optimization have been really impressive in the last years, in general they are still constrained to small or medium size problems. The performance of these algorithms is highly dependent on the structure of the mathematical model, type of nonconvexities, etc. In MINLP models the difficulty increases because in addition to the 
inherent difficulty of the continuous problems in continuous global optimization, there is the discrete nature of the problem. The problem dealt with in this study is a medium to large MINLP problem with a large number of non-convex equations, thus, a global optimal solution cannot be ensured. Moreover, experience shows that getting trapped in bad local solutions is not uncommon.

It is crucial to note that to set a good starting point it is necessary to give all the possible flexibility in the lower and upper variables limits, prior to solve the model, i.e., it is important to fix very low lower bounds and very high upper limits to the most influenced variables, as the Reynolds number, for example.

\section{Conclusions}

In the present paper a model for the optimal design of shell-and-tube heat exchangers (STHEs) was proposed. It is a MINLP model that follows rigorously the Standards of TEMA. Thus, geometric characteristics as shell diameter, outlet tube bundle diameter, tube arrangement, tube length, tube pitch, internal and external tube diameters, number of baffles, baffle spacing, number of tube passes, number of shells and number of tubes are in accordance with TEMA standards, avoiding the adjustment of heat exchanger parameters after the design task. A tube counting table was proposed and the use of GDP makes the optimization task simpler, avoiding nonlinearities in the model. The method of Bell-Delaware is used to calculate the variables on the shell-side. The model calculates the best heat exchanger to a given set of temperatures, flowrates and fluids physical properties. The major contribution of this paper is the proposition of a sequential optimization approach to avoid solutions prematurely stuck in the local minimum. With this aim, the design equations were 
divided into sets, with the proposition of different objective functions for the optimization of each set of equations.

The problem was solved with GAMS, using the solver SBB for the MINLP problems and the solver CONOPT3 for the NLP problems. During the solution of the model, the major problems were found in the initialization of the variables limits. Three examples from the literature were studied to evaluate the applicability of the proposed model. The results obtained with this model are better than those reported in the literature, considering the two situations of whether or not to fix the location of the fluids in the heat exchanger. This improvement in the results is achieved due to the use of multiple objective functions in a sequential optimization approach.

\section{Nomenclature}

$\begin{array}{ll}\text { A } & \text { heat exchange area } \\ a_{c} & \text { cost constant } \\ \text { arr } & \text { tube arrangement } \\ b_{c} & \text { cost constant } \\ \mathrm{c}_{\mathrm{c}} & \text { pumping cost constant } \\ \text { Cp } & \text { heat capacity } \\ \text { dex } & \text { tube external diameter } \\ \text { din } & \text { tube internal diameter } \\ \text { Dotl } & \text { tube bundle diameter } \\ \text { Ds } & \text { shell external diameter } \\ \text { FC } & \text { fraction of total tubes in cross-flow } \\ f l & \text { Fanning's factor }\end{array}$




\begin{tabular}{|c|c|}
\hline Fsbp & fraction of cross-flow area available for bypass \\
\hline$F t$ & correction factor of LMTD \\
\hline$h_{0} i$ & shell-side heat transfer coefficient for an ideal tube bank \\
\hline$h^{s}$ & shell-side film coefficient \\
\hline$h^{t}$ & tube-side film coefficient \\
\hline$J b$ & correction factor for bundle-bypassing effects \\
\hline$J_{C}$ & correction factor for baffle configuration effects \\
\hline ji & Colburn's factor \\
\hline$J l$ & correction factor for baffle-leakage effects \\
\hline$L$ & tube length \\
\hline lc & baffles cut \\
\hline LMTD & log mean temperature difference \\
\hline ls & baffle spacing \\
\hline$m$ & mass flowrate \\
\hline$N b$ & number of baffles \\
\hline Nc & number of tube rows crossed in one cross-flow section \\
\hline Ncw & number of tube columns effectively crossed in each window \\
\hline$N_{S}$ & number of shells \\
\hline$N t$ & number of tubes \\
\hline Ntp & number of tube passes \\
\hline $\mathrm{Nu}$ & number of Nusselt \\
\hline$C_{\text {area }}$ & area cost \\
\hline$C_{\text {pump }}$ & pumping cost \\
\hline$C_{\text {total }}$ & total cost \\
\hline $\operatorname{Pr}$ & number of Prandtl \\
\hline
\end{tabular}




\begin{tabular}{|c|c|}
\hline$p n$ & tube pitch normal to flow \\
\hline$p p$ & tube pitch parallel to flow \\
\hline$p t$ & tube pitch \\
\hline$Q$ & heat duty \\
\hline$R b$ & pressure drop correction factor for bundle- bypassing effects \\
\hline Re & Reynolds number \\
\hline$r d$ & fouling factor \\
\hline$R l$ & pressure drop correction factor for baffle-leakage effects \\
\hline Sm & reference normal area for shell-side flow \\
\hline Ssb & shell-to-baffle leakage \\
\hline$S t b$ & area tube-to-baffle leakage \\
\hline Sw & area for one baffle area flow thought the window \\
\hline$T$ & temperature \\
\hline$U c$ & clean overall heat transfer coefficient \\
\hline$U d$ & dirty overall heat transfer coefficient \\
\hline$v$ & fluid velocity \\
\hline$y^{f}$ & binary variable which defines the fluid allocation \\
\hline$y^{L}$ & binary variable which defines the tube length \\
\hline$y^{a r r}$ & binary variable which defines tube pattern arrangement \\
\hline$y^{n t}$ & binary variable which defines the variables of Table 1 \\
\hline$\varepsilon$ & roughness \\
\hline$\triangle P$ & pressure drop \\
\hline$\Delta P_{b i}$ & pressure drop for ideal cross-flow \\
\hline$\Delta P_{w i}$ & pressure drop for the window \\
\hline$k$ & thermal conductivity \\
\hline
\end{tabular}


viscosity

$\rho$

density

Acronyms:

GAMS

general algebraic modeling system

GDP

generalized disjunctive programming

MILP

mixed integer linear programming

MINLP

mixed integer non-linear programming

NLP

non-linear programming

STHE

shell-and-tube heat exchanger

TEMA

tubular exchanger manufacturers association

Subscript:

C

cold fluid

h

hot fluid

S

shell-side

$\mathrm{t}$

tube-side

in

inlet

out

outlet

\section{Acknowledgments}

This study was supported by “Coordenação de Aperfeiçoamento de Pessoal de Nível Superior - CAPES”, under process No. 10758/12-7, Brazil. José A. Caballero acknowledge the Spanish "Ministerio de Ciencia e Innovación” and "Ministerio de Economia y Competitividad” for the financial support under projects CTQ200914420-C02-02 and CTQ2012-37039-C02-02. 


\section{References}

[1] X. Cheng, X. Liang, Computation of effectiveness of two-stream heat exchanger networks based on concepts of entropy generation, entransy dissipation and entransy-dissipation-based thermal resistance, Energ. Convers. Manage. 58 (2012) 163-170.

[2] R.S. Kaluri, T. Basak, Entropy generation due to natural convection in discretely heated porous square cavities, Energy. 36 (2011) 5065-5080.

[3] R.Z. Wang, Z.Z. Xia, L.W. Wang, Z.S. Lu, S.L. Li, J.Y. Wu, et al, Heat transfer design in adsorption refrigeration systems for efficient use of low-grade thermal energy, Energy. 36 (2011) 5425-5439.

[4] X. Cheng, X. Liang, Optimization principles for two-stream heat exchangers and two-stream heat exchanger networks, Energy. 46 (2012) 386-392.

[5] A.V. Azad, M. Amidpour, Economic optimization of shell and tube heat exchanger based on constructal theory, Energy. 36 (2011) 1087-1096.

[6] V.K. Patel, R.V. Rao, Design optimization of shell-and-tube heat exchanger using particle swarm optimization technique, Appl. Therm. Eng. 30 (2010) 14171425.

[7] M.A.S.S. Ravagnani, J.A. Caballero, A MINLP model for the rigorous design of shell and tube heat exchangers using the TEMA standards, Chem. Eng. Res. Des. 85 (2007) 1-13.

[8] S. Rajasekaran, T. Kannadasan, Optimization of Shell and Tube Heat Exchangers Using modified Genetic Algorithm, Int. J. Control. Autom. 3 (2010) 110. 
networks with genetic algorithms for designing each heat exchanger including condensers, Appl. Therm. Eng. 29 (2009) 3437-3444.

[10] J.M. Ponce-Ortega, M. Serna-González, A. Jiménez-Gutiérrez, Use of genetic algorithms for the optimal design of shell-and-tube heat exchangers, Appl. Therm. Eng. 29 (2009) 203-209.

[11] J. Guo, L. Cheng, M. Xu, Optimization design of shell-and-tube heat exchanger by entropy generation minimization and genetic algorithm, Appl. Therm. Eng. 29 (2009) 2954-2960.

[12] F.T. Mizutani, F.L.P. Pessoa, E.M. Queiroz, S. Hauan, I.E. Grossmann, Mathematical programming model for heat-exchanger network synthesis including detailed heat-exchanger designs. 1. Shell-and-tube heat-exchanger design, Ind. Eng. Chem. Res. 42 (2003) 4009-4018.

[13] J.M. Ponce-Ortega, M. Serna-González, L.I. Salcedo-Estrada, A. JiménezGutiérrez, Minimum-investment design of multiple shell and tube heat exchangers using a MINLP formulation, Chem. Eng. Res. Des. 84 (2006) 905-910.

[14] T.A. Pogiatzis, D.I. Wilson, V.S. Vassiliadis, Scheduling the cleaning actions for a fouled heat exchanger subject to ageing: MINLP formulation, Comput. Chem. Eng. 39 (2012) 179-185.

[15] M. Li, A.C.K. Lai, Thermodynamic optimization of ground heat exchangers with single U-tube by entropy generation minimization method, Energ. Convers. Manage. 65 (2013) 133-139.

[16] B. David, J. Ramousse, L. Luo, Optimization of thermoelectric heat pumps by operating condition management and heat exchanger design, Energ. Convers. Manage. 60 (2012) 125-133. 
[17] B.K. Soltan, M. Salffar-Avval, E. Damangir, Minimizing capital and operating costs of shell and tube condensers using optimum baffle spacing, Appl. Them. Eng. 24 (2004) 2801-2810.

[18] H. Li, V. Kottke, Effect of baffle spacing on pressure drop and local heat transfer in shell-and-tube heat exchangers for staggered tube arrangement, Int. J. Heat Mass Transfer. 41 (1998) 1303-1311

[19] M. Fesanghary, E. Damangir, I. Soleimani, Design optimization of shell and tube heat exchangers using global sensitivity analysis and harmony search algorithm, Appl. Therm. Eng. 29 (2009) 1026-1031.

[20] D.Q. Kern, Process Heat Transfer, McGraw-Hill, New York, 1950.

[21] J. Taborek, Shell-and-Tube Heat Exchangers. Newport: Hemisphere publishing, 1983.

[22] TEMA, Standards of the Tubular Exchangers Manufactures Association, ninth ed, Tubular Exchanger Manufacturers Association, New York, 2007.

[23] R. Smith, Chemical Process Design and Integration, second ed, Wiley, 2005.

[24] A. Vecchietti, S. Lee, I.E. Grossmann, Modeling of discrete/continuous optimization problems: characterization and formulation of disjunctions and their relaxations, Comput. Chem. Eng. 27 (2003) 433-448.

[25] I.E. Yeomans, H., \& Grossmann, Nonlinear disjunctive programming models for the synthesis of heat integrated distillation sequences., Comput. Chem. Eng. 23 (1999) 1135-1151.

[26] W.W. Blackwell, L. Haydu, Calculating the correct LMDT in shell-and-tube heat exchangers, Chem. Eng. 88 (1981) 101-106. 
[27] S.G. Hall, S. Ahmad, R. Smith, Capital cost targets for heat exchanger networks comprising mixed materials of construction, pressure ratings and exchanger types. Comput. Chem. Eng. 14 (1990) 319-335.

[28] U.V. Shenoy, Heat Exchanger Network Synthesis: Process Optimization by Energy and Resource Analysis, Houston: Gulf Publishing Company, 1995.

[29] J.J. Chen, Letter to the editor: Comments on improvement on a replacement for the logarithmic mean, Chem. Eng. Sci. 42 (1987) 2488.

[30] M. Serna, M.A. Jiménez, An efficient method for the design of shell and tube heat exchangers, Heat Transfer Eng. 25 (2004) 5-16.

[31] M. Serna, A. Jimenez, A compact formulation of the Bell-Delaware method for heat exchanger design and optimization, Chem. Eng. Res. Des. 83 (2005) 539550.

[32] A.C. Caputo, P.M. Pelagagge, P. Salini, Heat exchanger design based on economic optimization. Appl. Them. Eng. 28 (2008) 1151-1159.

[33] R.K. Shah, D.P. Sekulic, Fundamentals of Heat Exchanger Design, New York, Wiley, 2003. 


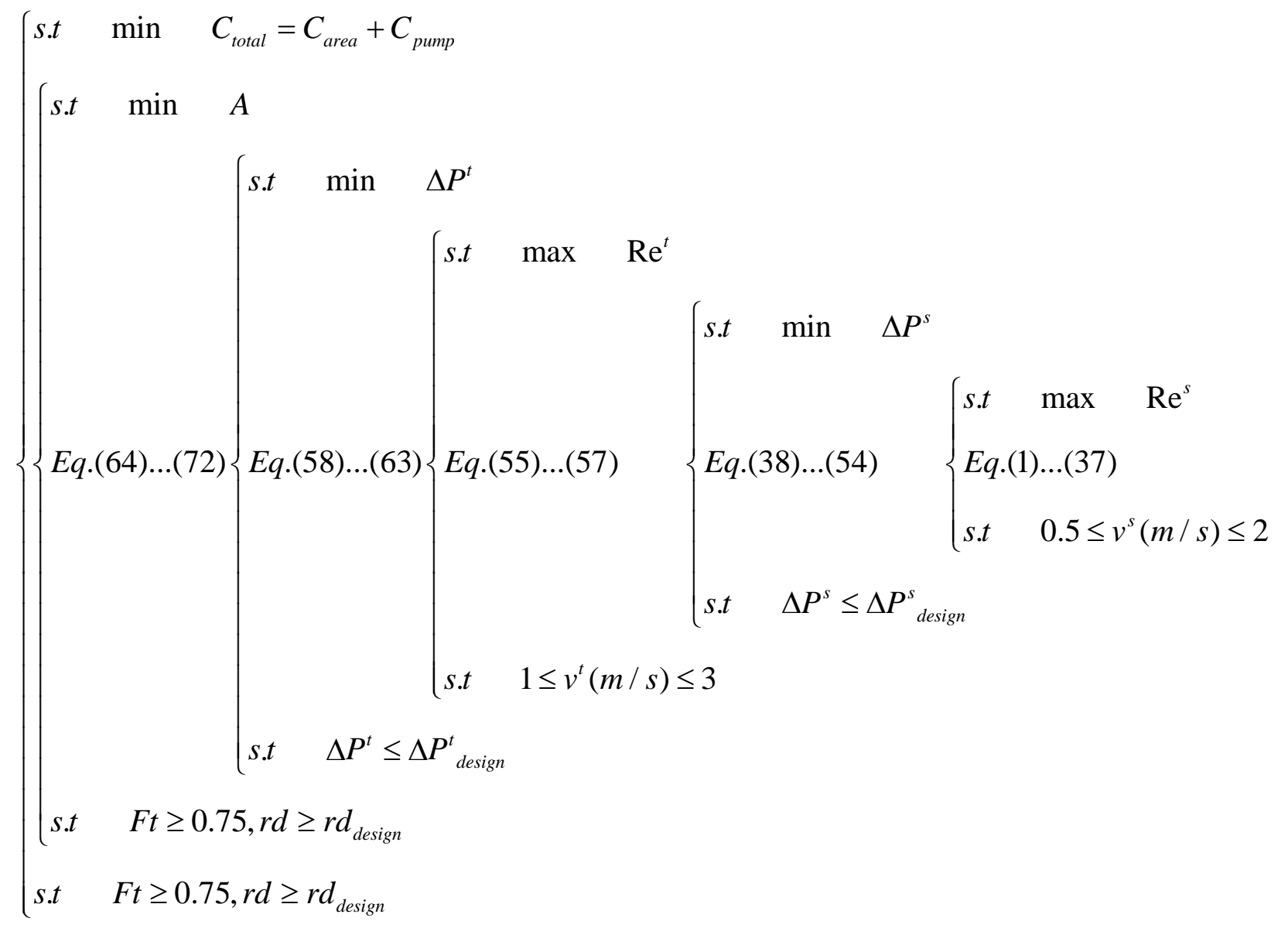

Fig 1. Scheme for sequential optimization of STHEs. 
Table 1

Tube counting table proposed according to TEMA standards.

\begin{tabular}{ccccccc}
\hline $\operatorname{Ds}(m)$ & $\operatorname{Dotl}(m)$ & $\operatorname{dex}(m)$ & $\operatorname{Arr}$ & $p t(m)$ & $N t p$ & $N t$ \\
\hline 0.205 & 0.17325 & 0.01905 & 1 & 0.02379 & 1 & 38 \\
0.205 & 0.17325 & 0.01905 & 1 & 0.02379 & 2 & 32 \\
0.205 & 0.17325 & 0.01905 & 1 & 0.02379 & 4 & 26 \\
0.205 & 0.17325 & 0.01905 & 1 & 0.02379 & 6 & 24 \\
. &. &. &. & $\cdot$ &. &. \\
. &. & $\cdot$ & $\cdot$ & $\cdot$ &. &. \\
1.524 & 1.47300 & 0.02540 & 2 & 0.03175 & 6 & 1553 \\
1.524 & 1.47300 & 0.02540 & 2 & 0.03175 & 8 & 1522 \\
\hline
\end{tabular}


Table 2

Data process input and physical properties for different case studies.

\begin{tabular}{ccccccccc}
\hline$T_{\text {in }}$ & $T_{\text {out }}$ & $m$ & $\mu$ & $\rho$ & $C p$ & $k$ & $r_{d}$ \\
$(\mathrm{~K})$ & $(\mathrm{K})$ & $(\mathrm{kg} / \mathrm{s})$ & $(\mathrm{kg} / \mathrm{ms})$ & $\left(\mathrm{kg} / \mathrm{m}^{3}\right)$ & $(\mathrm{J} / \mathrm{kgK})$ & $(\mathrm{W} / \mathrm{mK})$ & $(\mathrm{W} / \mathrm{mK})$ \\
\hline
\end{tabular}

\section{Case 1:}

$\begin{array}{lrrrrrrrr}\text { Hot } & 371.15 & 338.15 & 14.90 & 2.3 \mathrm{e}-4 & 777 & 2684 & 0.110 & 1.5 \mathrm{e}-4 \\ \text { Cold } & 288.15 & 298.15 & 31.58 & 1.0 \mathrm{e}-3 & 998 & 4180 & 0.600 & 1.5 \mathrm{e}-4\end{array}$

\section{Case 2:}

$\begin{array}{lrrrrrrrr}\text { Hot } & 368.15 & 313.75 & 27.78 & 3.4 \mathrm{e}-4 & 750 & 2840 & 0.190 & 1.5 \mathrm{e}-4 \\ \text { Cold } & 298.15 & 313.15 & 68.88 & 8.0 \mathrm{e}-4 & 995 & 4200 & 0.590 & 1.5 \mathrm{e}-4\end{array}$

Case 3:

$\begin{array}{lllllllll}\text { Hot } & 483.15 & 377.59 & 19.15 & 1.2 \mathrm{e}-4 & 790 & 2428 & 0.106 & 3.5 \mathrm{e}-4 \\ \text { Cold } & 324.81 & 355.37 & 75.22 & 2.9 \mathrm{e}-4 & 820 & 2135 & 0.123 & 3.5 \mathrm{e}-4\end{array}$


Table 3

Optimal geometry obtained for the heat exchanger in case study 1.

\begin{tabular}{|c|c|c|c|c|c|c|c|}
\hline & [28] & {$[7]^{a}$} & {$[7]^{b}$} & $\begin{array}{c}\text { Present } \\
\text { work }^{a, 1}\end{array}$ & $\begin{array}{c}\text { Present } \\
\text { work }^{b, 1}\end{array}$ & $\begin{array}{c}\text { Present } \\
\text { work }^{a, 2}\end{array}$ & $\begin{array}{l}\text { Present } \\
\text { work }^{b, 2}\end{array}$ \\
\hline \multicolumn{8}{|l|}{ SET 1} \\
\hline$D s(\mathrm{~m})$ & 0.549 & 0.438 & 0.533 & 0.438 & 0.387 & 0.438 & 0.337 \\
\hline $\operatorname{Dotl}(\mathrm{m})$ & 0.516 & 0.406 & 0.489 & 0.406 & 0.356 & 0.406 & 0.305 \\
\hline$N t$ & 318 & 194 & 264 & 194 & 132 & 181 & 95 \\
\hline ls (m) & 0.192 & 0.105 & 0.122 & 0.438 & 0.383 & 0.213 & 0.163 \\
\hline Ntp & 6 & 4 & 2 & 4 & 2 & 4 & 1 \\
\hline $\operatorname{dex}(\mathrm{mm})$ & 19.10 & 19.05 & 19.05 & 19.05 & 19.05 & 19.05 & 19.05 \\
\hline $\operatorname{din}(\mathrm{mm})$ & 15.40 & 17.00 & 17.00 & 17.00 & 17.00 & 17.00 & 17.00 \\
\hline$L(\mathrm{~m})$ & 1.286 & 2.438 & 2.438 & 2.438 & 3.658 & 2.438 & 4.877 \\
\hline$v^{s}(\mathrm{~m} / \mathrm{s})$ & - & 0.935 & 1.162 & 0.827 & 0.517 & 1.355 & 1.400 \\
\hline Arr & Square & triang. & square & triang. & square & triang. & square \\
\hline$p t(\mathrm{~mm})$ & 25.40 & 25.40 & 25.40 & 23.79 & 25.40 & 25.40 & 25.40 \\
\hline $\begin{array}{l}\text { Hot fluid } \\
\text { allocation }\end{array}$ & Shell & tube & shell & tube & shell & tube & shell \\
\hline$R e^{s}$ & - & - & - & 13260 & 60343 & 38134 & 100000 \\
\hline \multicolumn{8}{|l|}{ SET 2} \\
\hline$N b$ & - & - & - & 5 & 9 & 10 & 29 \\
\hline$f i^{s}$ & - & - & - & 0.108 & 0.109 & 0.108 & 0.109 \\
\hline$L c$ & - & - & - & 0.110 & 0.097 & 0.110 & 0.084 \\
\hline$P r^{s}$ & - & - & - & 6.967 & 5.612 & 6.967 & 5.612 \\
\hline
\end{tabular}


$\begin{array}{llllllll}h^{\mathrm{s}}\left(\mathrm{W} / \mathrm{m}^{2 \mathrm{o}} \mathrm{C}\right) & 1364.5 & 3831.38 & 1308.36 & 5162.56 & 2095.99 & 7782.9 & 2969.83\end{array}$

$\begin{array}{llllllll}\Delta P^{S}(\mathrm{kPa}) & 3.60 & 7.00 & 7.00 & 10.00 & 10.00 & 59.987 & 60.00\end{array}$

\section{SET 3}

$\begin{array}{lccccccc}v^{t}(\mathrm{~m} / \mathrm{s}) & - & 1.827 & 1.108 & 1.827 & 2.215 & 1.958 & 1.539 \\ \operatorname{Re}^{t} & - & - & - & 102452 & 36700 & 109810 & 25497\end{array}$

\section{SET 4}

$\begin{array}{lccccccc}\operatorname{Pr}^{t} & - & - & - & 5.612 & 6.967 & 5.612 & 6.967 \\ N u^{t} & - & - & - & 489.2 & 231.3 & 517.1 & 172.8 \\ h^{t}\left(\mathrm{~W} / \mathrm{m}^{20} \mathrm{C}\right) & 8649.6 & 2759.84 & 4087.06 & 2824.77 & 7283.92 & 2985.94 & 5442.78 \\ \Delta P^{t}(\mathrm{kPa}) & 42.00 & 26.92 & 7.706 & 33.00 & 43.04 & 37.83 & 13.31\end{array}$

SET 5

$\begin{array}{llllllll}Q(\mathrm{~kW}) & 1320 & 1320 & 1320 & 1320 & 1320 & 1320 & 1320\end{array}$

$\begin{array}{llllllll}\text { LMTD } & 88.60 & 88.56 & 88.56 & 60.78 & 60.78 & 60.78 & 60.78\end{array}$

$\begin{array}{llllllll}U d\left(\mathrm{~W} / \mathrm{m}^{20} \mathrm{C}\right) & 776.00 & 779.07 & 572.51 & 778.96 & 763.01 & 834.90 & 795.19\end{array}$

$\begin{array}{llllllll}U_{C}\left(\mathrm{~W} / \mathrm{m}^{2 \mathrm{o}} \mathrm{C}\right) & 1000.70 & 1017.88 & 7122.42 & 1054.49 & 1017.28 & 1161.20 & 1116.16\end{array}$

$\begin{array}{llllllll}\text { Ft } & 0.9 & 0.9 & 0.9 & 0.985 & 0.985 & 0.985 & 0.985\end{array}$

$r d\left(\mathrm{~m}^{20} \mathrm{C} / \mathrm{W}\right) \quad 4.1 \mathrm{e}-3 \quad 3.01 \mathrm{e}-4 \quad 3.43 \mathrm{e}-4 \quad 3.35 \mathrm{e}-4 \quad 3.28 \mathrm{e}-4 \quad 3.37 \mathrm{e}-4 \quad 3.62 \mathrm{e}-4$ $\begin{array}{llllllll}A\left(\mathrm{~m}^{2}\right) & 28.40 & 28.31 & 38.52 & 28.31 & 28.89 & 26.41 & 27.73\end{array}$

\footnotetext{
${ }^{a}$ without specifying the location of the hot fluid inside the exchanger

${ }^{b}$ fixing the hot fluid in the shell-side

${ }^{1}$ pressure in shell-side $=10 \mathrm{kPa}$ and pressure in tube-side $=45 \mathrm{kPa}$

${ }^{2}$ pressure in both sides $=60 \mathrm{kPa}$
} 


\section{Table 4}

Optimal geometry obtained for the heat exchanger in case study 2.

\begin{tabular}{|c|c|c|c|c|c|}
\hline & {$[12]$} & {$[7]^{a}$} & {$[7]^{b}$} & Present work $^{a}$ & Present work $^{b}$ \\
\hline \multicolumn{6}{|l|}{ SET 1} \\
\hline Ds (m) & 0.687 & 1.067 & 0.838 & 0.940 & 0.787 \\
\hline $\operatorname{Dotl}(\mathrm{m})$ & 0.672 & 1.022 & 0.796 & 0.895 & 0.746 \\
\hline$N t$ & 832 & 680 & 713 & 544 & 616 \\
\hline ls $(\mathrm{m})$ & 0.542 & 0.610 & 0.353 & 0.737 & 0.376 \\
\hline Ntp & 2 & 8 & 2 & 6 & 2 \\
\hline $\operatorname{dex}(\mathrm{mm})$ & 15.90 & 25.04 & 19.05 & 25.04 & 19.05 \\
\hline $\operatorname{din}(\mathrm{mm})$ & 12.60 & 23.00 & 16.00 & 22.10 & 17.00 \\
\hline$L(\mathrm{~m})$ & 4.88 & 4.88 & 6.71 & 6.096 & 6.706 \\
\hline$v^{\mathrm{s}}(\mathrm{m} / \mathrm{s})$ & - & 0.500 & 0.500 & 0.500 & 0.500 \\
\hline$A r r$ & square & square & square & square & square \\
\hline Hot fluid allocation & shell & tube & shell & Tube & shell \\
\hline$R e^{s}$ & - & - & - & 8308.4 & 21013.8 \\
\hline \multicolumn{6}{|l|}{ SET 2} \\
\hline$N b$ & 8 & 7 & 18 & 7 & 17 \\
\hline$f i^{s}$ & - & - & - & 0.108 & 0.108 \\
\hline$L c$ & - & - & - & 0.235 & 0.197 \\
\hline$P r^{s}$ & - & - & - & 5.695 & 5.082 \\
\hline$h^{s}\left(\mathrm{~W} / \mathrm{m}^{2 \mathrm{o}} \mathrm{C}\right)$ & 1829 & 3240 & 1516 & 2921 & 1880.2 \\
\hline$\Delta P^{s}(\mathrm{kPa})$ & 7.494 & 4.431 & 6.445 & 4.486 & 10.609 \\
\hline SET 3 & & & & & \\
\hline
\end{tabular}




\begin{tabular}{|c|c|c|c|c|c|}
\hline$v^{t}(\mathrm{~m} / \mathrm{s})$ & - & 1.058 & 1.003 & 1.027 & 1.039 \\
\hline$R e^{t}$ & - & - & - & 50997 & 21441.5 \\
\hline \multicolumn{6}{|l|}{ SET 4} \\
\hline $\operatorname{Pr}^{t}$ & - & - & - & 5.082 & 5.695 \\
\hline$N u^{t}$ & - & - & - & 270.9 & 140.7 \\
\hline$h^{t}\left(\mathrm{~W} / \mathrm{m}^{2 o} \mathrm{C}\right)$ & 6480 & 1986 & 4186 & 2026 & 4356.7 \\
\hline$\Delta P^{t}(\mathrm{kPa})$ & 22.676 & 23.312 & 13.404 & 22.829 & 15.921 \\
\hline \multicolumn{6}{|l|}{ SET 5} \\
\hline$Q(\mathrm{~kW})$ & 4339 & 4339 & 4339 & 4339.4 & 4339.4 \\
\hline$A\left(\mathrm{~m}^{2}\right)$ & 202.0 & 264.6 & 286.6 & 264.62 & 247.22 \\
\hline LMTD & - & - & - & 31.27 & 31.27 \\
\hline$U d\left(\mathrm{~W} / \mathrm{m}^{2 o} \mathrm{C}\right)$ & - & 655.298 & 606.019 & 637.38 & 682.23 \\
\hline$U_{C}\left(\mathrm{~W} / \mathrm{m}^{20} \mathrm{C}\right)$ & 860 & 826.687 & 758.664 & 800.26 & 874.41 \\
\hline$F t$ & - & - & - & 0.823 & 0.823 \\
\hline Area cost (\$/year) & 2826.00 & 3495.36 & 3663.23 & 3305.64 & 3175.61 \\
\hline Pumping cost & & & & & \\
\hline (\$/year) & 2424.00 & 1532.93 & 1528.24 & 1514.58 & 1958.59 \\
\hline $\begin{array}{l}\text { Total annual cost } \\
\text { (\$/year) }\end{array}$ & 5250.00 & 5028.29 & 5191.47 & 4820.22 & 5134.21 \\
\hline
\end{tabular}


Table 5

Optimal geometry obtained for the heat exchanger in case study 3.

\begin{tabular}{|c|c|c|c|}
\hline & [30] & [7] & Present work \\
\hline \multicolumn{4}{|l|}{ SET 1} \\
\hline Ds (m) & 0.770 & 0.737 & 0.686 \\
\hline $\operatorname{Dotl}(\mathrm{m})$ & 0.715 & 0.659 & 0.645 \\
\hline$N t$ & 528 & 509 & 286 \\
\hline ls $(\mathrm{m})$ & 0.406 & 0.305 & 0.595 \\
\hline Ntp & 6 & 6 & 8 \\
\hline $\operatorname{dex}(\mathrm{mm})$ & 19.05 & 19.05 & 25.04 \\
\hline $\operatorname{din}(\mathrm{mm})$ & 14.83 & 17.00 & 22.90 \\
\hline$L(\mathrm{~m})$ & 5.28 & 4.88 & 6.096 \\
\hline$v^{s}(\mathrm{~m} / \mathrm{s})$ & - & - & 1.123 \\
\hline$A r r$ & triangular & triangular & triangular \\
\hline Hot fluid allocation & tube & tube & tube \\
\hline$R e^{s}$ & - & - & 100000 \\
\hline \multicolumn{4}{|l|}{ SET 2} \\
\hline $\mathrm{Nb}$ & 18 & 15 & 9 \\
\hline$f i^{s}$ & - & - & 0.109 \\
\hline$L c$ & - & - & 0.171 \\
\hline$P r^{s}$ & - & - & 5.034 \\
\hline$h^{s}\left(\mathrm{~W} / \mathrm{m}^{20} \mathrm{C}\right)$ & - & - & 2848 \\
\hline$\Delta P^{S}(\mathrm{kPa})$ & 83.630 & 43.690 & 43.690 \\
\hline SET 3 & & & \\
\hline
\end{tabular}




\begin{tabular}{|c|c|c|c|}
\hline$v^{t}(\mathrm{~m} / \mathrm{s})$ & - & - & 1.647 \\
\hline$R e^{t}$ & - & - & 248191 \\
\hline \multicolumn{4}{|l|}{ SET 4} \\
\hline $\operatorname{Pr}^{t}$ & - & - & 2.749 \\
\hline$N u^{t}$ & - & - & 782.7 \\
\hline$h^{t}\left(\mathrm{~W} / \mathrm{m}^{2 o} \mathrm{C}\right)$ & & & 3266 \\
\hline$\Delta P^{t}(\mathrm{kPa})$ & 78.805 & 76.738 & 75.497 \\
\hline \multicolumn{4}{|l|}{ SET 5} \\
\hline$Q(\mathrm{~kW})$ & 4909.1 & 4909.1 & 4909.1 \\
\hline LMTD & - & - & 84.83 \\
\hline$U d\left(\mathrm{~W} / \mathrm{m}^{20} \mathrm{C}\right)$ & 385.1 & 425.1 & 453.8 \\
\hline$U_{C}\left(\mathrm{~W} / \mathrm{m}^{20} \mathrm{C}\right)$ & - & - & 685.79 \\
\hline Ft & - & 0.9165 & 0.917 \\
\hline$r d\left(\mathrm{~m}^{2 o} \mathrm{C} / \mathrm{W}\right)$ & - & - & $7.45 e-4$ \\
\hline$A\left(\mathrm{~m}^{2}\right)$ & 163.97 & 148.56 & 139.12 \\
\hline
\end{tabular}

